\title{
OUTCOMES OF VIDEO ASSISTED THORACOSCOPIC DECORTICATION VERSUS CONVENTIONAL OPEN DECORTICATION IN PATIENTS WITH STAGE II OR STAGE III EMPYEMA
}

\author{
Ibrahim Baloch, Bilal Umair, Asif Asghar, Muhammad Imtiaz Khan, Muhammad Shoaib Hanif, Azfar Bilal \\ Combined Military Hospital/National University of Medical Sciences (NUMS) Rawalpindi Pakistan
}

\begin{abstract}
Objective: To compare outcomes of video assisted Thoracoscopic Decortication (VATD) with conventional open decortication (COD) in patients with stage-II or stage-III empyema thoracic.

Study Design: Prospective comparative study.

Place and Duration of Study: Department of Thoracic Surgery, Combined Military Hospital, Rawalpindi, Pakistan, from Jun 2018 to May 2019.

Methodology: A total 60 patients underwent in this study. Patients of both gender who reported for decortication of empyema thoracic were evaluated. All patients diagnosed to have Stage II or III empyema with age 25-50 years were studied for outcomes. All patients were evaluated for operative time, blood loss, post-operative pain, pneumonitis, duration of airleak and post-operative drainage, duration of chest drains and length of hospital stay.

Results: Mean operative time in group- 1 was $133.63 \pm 8.55 \mathrm{~min}$ and in group-2 was $147.83 \pm 10.36$ min ( $p$-value 0.037). Mean blood loss in group-1 was $296.66 \pm 46.11$ while in group- 2 was $207.30 \pm 53.81$. Post-operative pain score on VAS for pain was $5.8 \pm 1.7$ for group-1 and $4.06 \pm 1.4$ for group- 2 ( $p$-value 0.032 ). Chest tubes were retained for an average of $5.58 \pm 0.8$ days in group-1 while $3.86 \pm 0.8$ days in group-2 ( $p$-value $<0.001)$.

Conclusion: Video-Assisted Thoracoscopic Surgery Decortication is superior to open decortication in operative management of Stage II and Stage III Empyema thoracic in terms of post op pain, duration of chest intubation, air leak and hospital stay of the patient.
\end{abstract}

Keywords: Conventional open decortications (COD), Empyema thoracic, Video-assisted thoracoscopic decortication (VATD).

This is an Open Access article distributed under the terms of the Creative Commons Attribution License (https://creativecommons.org/licenses/by-nc/4.0/), which permits unrestricted use, distribution, and reproduction in any medium, provided the original work is properly cited.

\section{INTRODUCTON}

Empyema thoracic is one of the common thoracic diseases worldwide with a persistently increasing incidence ${ }^{1}$. Community acquired pneumonia is the most common cause of empyema the incidence rate in adult estimated at 4.63 per 1000 persons/year. Other causes include TB, lung abscess, Bronchopleural fistula, esophageal perforation, postsurgical complications, and tra$u^{2}{ }^{2}$. Empyema thoracic is associated with a high rate of morbidity and long duration of hospitalization in affected patients especially with a complex disease ${ }^{3}$. Empyema can be classified into three stages; stage-1 (exudative) include one or more of pleural fluid $(\mathrm{pH}$ $<7.2$, glucose $<40 \mathrm{mg} / \mathrm{dL}, \mathrm{LDH}>1000 \mathrm{IU} / \mathrm{dL}$, protein $>2.5 \mathrm{~g} / \mathrm{dL}, \mathrm{WBC}>500 / \mu \mathrm{L}$, specific gravity $>1.018$, thin serous or cloudy fluid it is generally sterile), stage-2 (fibrinopurulent) include thicker, opaque with positive cultures, early stage- 3 include organizing thin peel and stage-3 (organizing) include an organizing peel with entrapment of the lung 4 . Stage- 1 disease can often be managed either by needle aspiration and tube Thora-

Correspondence: Dr Ibrahim Baloch, Department of Thoracic Surgery, Combined Military Hospital, Rawalpindi Pakistan

Received: 05 Oct 2020; revised received: 16 Dec 2020; accepted: 18 Dec 2020 costomy along with antiboitics 5 . Surgery is the definitive option for the management of stage-2 and stage- 3 empyema.

The most common approach for decortication in stage-3 empyema is conventional open decortication (COD) ${ }^{6}$. Since video-assisted Thoracoscopic decortication (VATD) has gradually evolved in thoracic surgical procedures, researchers are focusing on minimally invasive pleural decortication in stage-3 empyema ${ }^{7}$. The aim of our study was to compare the outcomes of VATD with conventional open decortication for the treatment of stage-II or stage-III pleural empyema in terms of Operative time, Blood loss, Post-operative pain, pneumonitis, duration of airleak, duration of chest drains and length of hospital stay. The results of this study will help us to decide the management strategy (i.e. COD or VATD) which is ideal for being adopted for surgical management of pleural empyema. We herein report our institutional experience with the VATD versus COD approach for Decortications in empyema thoraces.

\section{METHODOLOGY}

This prospective comparative study was done at Combined Military Hospital (CMH) Rawalpindi, from 
June 2018 to May 2019. Sample size for this study calculated by using online sample size calculator for two means available at; http://www.openepi.com/ SampleSize/SSMean.htm.

By taking hospital stay $9.61 \pm 4.1$ days in VATS group versus $21.82 \pm 16.35$ days in COD group, and at power of the test $80 \%$ and level of significance $5 \%$. Sample size was calculated using WHO sample size calculator (confidence level 95\%, power $=80$ ). Sampling technique was non-probability consecutive sampling. The calculated sample size was 30 patients in each group.

After approval from the ERC/IERB the certificate number Sr-No: 01/08/19, the patients who presented in Thoracic Surgery department of CMH Rawalpindi with stage-II and stage-III empyema planned for surgical intervention were included in this study. All patients having empyema thoraces stage II and III with Unilocular cavities with underlying minimal lung consolidation meeting the inclusion criteria that was patients between 5-50 years of age of both genders were randomly distributed in group VATS and COS. Patients having stage I pleural empyema and patients Complex empyema's with underlying lung cavitation's were excluded from study. An informed consent was taken from all patients before including them in this study and by ensuring them the confidentiality of study data. These 60 patients assigned into two groups VATSD (VATD Decortication) and COD (Conventional open decortications) on the basis of selection by operating consultant by consecutive sampling. In group of VATD: video assisted thoracic surgery decortication was done and in group COD; conventional open thoracotomy decortication (COD) was done. Both of these procedures were done by consultant thoracic surgeons having at least 3 years of post-fellowship experience. The principal investigator served as assistant in all procedure. Data regarding study outcomes including Operative time, Blood loss measured by number of soaked gauzes (one soaked gauze equal to $100 \mathrm{ml}$ of blood) and suctioned blood, Post-operative pain, pneumonitis or post-operative pulmonary consolidating patches on chest x-ray with raise white blood cell, tachycardia and ongoing fever, duration of airleak and post-operative drainage, duration of chest drains and length of hospital stay were noted. Post-operative pain was measured by VAS (Visual analogue scale) ranging from 1-10 at $24 \mathrm{hrs}$. Interval post operatively (figure). All data was entered and analyzed using special package for social sciences (SPSS) v 20. Mean \& standard deviation were calculated for quantitative variables like operative time, blood loss, post op pain and hospital stay. For categorical variables like gender and operative morbidity, frequency and percentages were calculated. $p$ value $<0.05$ was taken as significant.

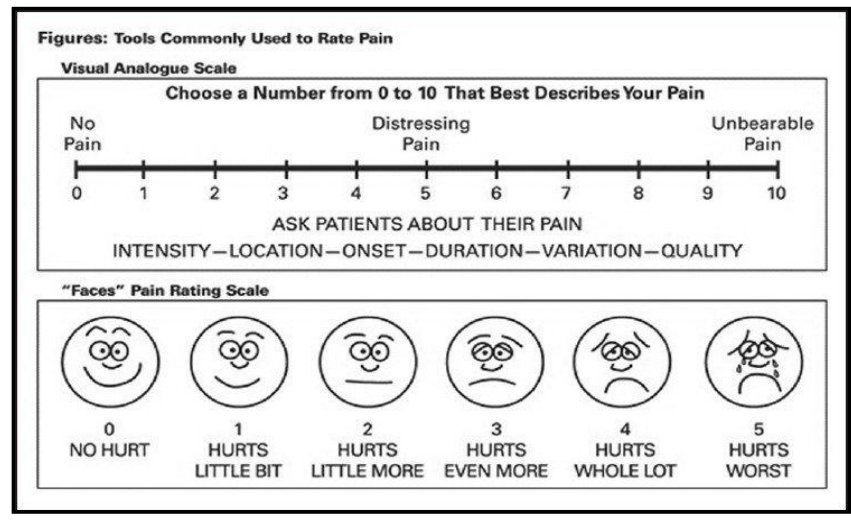

Figure: Visual analogue scale.

\section{RESULTS}

A total of 60 patients undergoing decortication for empyema thoraces were recruited and were assigned into two equal groups by consecutive sampling. Each group thus had 30 patients. VATD group (A) had 17 patients of stage II and 13 patients of early stage III empyema, while COD group (B) had 14 patients of stage II and 16 patients of stage III empyema. Minimum age was 20 years and maximum age was 50 years with mean age of $34.71+9.11$ years. Mean age in COD group was $35.90 \pm 9.38$ years while mean age in VATD group was $33.53 \pm 8.83$ years ( $p$-value 0.228 ). Out of total 60 patients, $44(73.3 \%)$ were males and $16(26.7 \%)$. COD group had $22(73.3 \%)$ and 16 (26.7\%) females with an equal frequency in VATD group with insignificant $p$-value of ${ }^{1}$. Mean operative time in COD was $133.63 \pm 8.55 \mathrm{~min}$ and in VATD was $147.83 \pm 10.36 \mathrm{~min}$. with a $p$-value of 0.037 . Mean blood loss in COD group was $296.66 \pm 46.11$ while in VATD, mean blood loss was $207.30 \pm 53.81$. The difference was statistically significant with $p$-value of 0.045 . Post-operative pain score on VAS for pain was $5.8 \pm 1.7$ for COD and $4.06 \pm 1.4$ for VATD. This difference was statistically significant with $p$ value of 0.032 . Chest tubes were retained for an average of $5.58 \pm 0.8$ days in COD while $3.86 \pm 0.8$ days in VATD group. ( $p$-value $<0.001$ ). Air leak duration was $3.66 \pm 1.36$ in COD group compared to $2.41 \pm 0.89$ in VATD group with $p$-value of 0.023 . Length of hospital stay in COD group was found to be $6.5 \pm 0.7$ as compared to VATD group where it was found to be $4.46 \pm$ 0.6 ( $p$-value $<0.001$ ). Post-operative pneumonitis was observed in 5 cases $(16.6 \%)$ in COD group as compa- 
red to $4(13.3 \%)$ cases in VATD group with an insignificant difference statistically ( $p$-value of 0.718 ).

Table-I: Distribution of gender in the two groups.

\begin{tabular}{l|c|c}
\hline \multirow{2}{*}{ Gender } & \multicolumn{2}{|c}{ Groups } \\
\cline { 2 - 3 } & $\begin{array}{c}\text { Conventional open } \\
\text { Thoracotomy } \\
\text { decortication (A), } \mathbf{n}(\%)\end{array}$ & $\begin{array}{c}\text { Video-assisted } \\
\text { Thoracoscopic } \\
\text { decortication (B), } \mathbf{n}(\%)\end{array}$ \\
\hline Male & $22(73.3)$ & $22(73.3)$ \\
\hline Female & $8(27.7)$ & $8(27.7)$ \\
\hline
\end{tabular}

of chronicity of the disease, rather than being confined to the standard procedure of a conventional open decor-tication (COD) and Decortication in late stage II and III empyema. With VATS decortication we have been able to achieve satisfactory success in lung expansion without the morbidity associated with open thoracotomy. Comparison of post-op parameters reflect the success of VATS Decortication such as short duration of operation time, duration of chest intubation, post-op hospital stay, and minimal peri-anesthesia morbidity ${ }^{11}$.

Table-II: Comparison of study variables in the two groups.

\begin{tabular}{|c|c|c|c|}
\hline \multirow[b]{2}{*}{ Outcome Variable } & \multicolumn{2}{|c|}{ Study Groups } & \multirow[b]{2}{*}{$p$-value } \\
\hline & $\begin{array}{c}\text { Conventional open thoracotomy } \\
\text { decortication (COD) }\end{array}$ & $\begin{array}{l}\text { Video-assisted thoracoscopic } \\
\text { decortication (VATD) }\end{array}$ & \\
\hline Operative time (minutes) & $133.63 \pm 8.55$ & $147.83 \pm 10.36$ & 0.037 \\
\hline Post-operative Pain on Day 1 (VAS) & $5.8 \pm 1.7$ & $4.06 \pm 1.4$ & 0.032 \\
\hline Amount of Blood loss (ml) & $296.66 \pm 46.11$ & $207.30 \pm 53.81$ & 0.045 \\
\hline $\begin{array}{l}\text { Duration of chest tube drainage post } \\
\text { operatively (No of days) }\end{array}$ & $5.58 \pm 0.8$ & $3.86 \pm 0.8$ & $<0.001$ \\
\hline Duration of Air leak (No of days) & $3.66 \pm 1.36$ & $2.41 \pm 0.89$ & 0.023 \\
\hline Length of hospital stay (No of days) & $6.5 \pm 0.7$ & $4.46 \pm 0.6$ & $<0.001$ \\
\hline Post-operative Pneumonitis (\%) & 16.6 & 13.3 & 0.718 \\
\hline
\end{tabular}

\section{DISCUSSION}

The mainstay of treatment of empyema thoraces is some form of decortication especially in patients where treatment is delayed by over a week and they develop multi-loculation in pleural cavity. This procedure is necessary because removal of all fibrinopurulent strands and the fibrotic tissue constricting the lung is of utmost importance for success of surgical therapy in empyema. Any remaining peel on the lung's surface does not allow complete re-expansion and a residual cavity is left behind which in turn leads to re-accumulation of pleural fluid collection. This re-accumulated fluid is now at high risk of getting infected particularly when the underlying pneumonia is not fully recovered $^{8}$. With the advancements in medical technology, VATD has emerged as a feasible management in StageII Empyema, when pleural drainage solely is insufficient. It has shown milestone results in different reports. This attractive Thoracoscopic approach has made the surgical intervention a more often acceptable initial treatment option ${ }^{9}$, as the technical expertise is improving more and more attempts of VATD are made in stage-III. VATS Decortication effectively, safely, and easily achieves re-expansion of the trapped underlying lung by removing the peel in the same way as in open surgery decortication ${ }^{10}$.

From our prior experience, we followed a general plan to operate VATS in all cases of empyema in spite
Our post-op results showed a significant difference in surgical procedure time of VATD and COD. The VATD time being more than the COD time. Duration of chest intubation and post-op hospital stay was short in patients who operated by VATD. VATD had lesser post-op pain, it is also observed that rapid wound healing and lesser post op wound infection in VATD while this study was not our prime study. Such findings have been noted by prior researchers who noticed that VATD has more advantages over open thoracotomy. These include shorter post-op hospital stay, reduced time of tube drainage, lesser post-op pain, shorter convalescence and early return to daily routine ${ }^{12}$.

During the stipulated study duration "pneumonia" was noted as the main complication in the majority of stage-3 patients whether they were managed with VATD or COD while two cases with significant pneumonia were recorded in stage-2 VATS Decortication. Other significant complications included atelectasis found in stage-2 empyema group and a few cases with air-leak, superficial wound infection and air space complications were seen in stage- 3 empyema patients. Complications found in patients after treatment in our study were in line with previous studies ${ }^{13}$. Most of the complications were represented by stage- 3 patients. No wound infection was found in stage- 3 empyema patients who operated by VATD while two patients who were operated by COD got their wounds infected. 
This could be considered as an advantage of VATD over COD for Stage-3 empyema patients.

Post-op hospital stay is a major predictor of selection of appropriate procedure for surgical management of pleural empyema. A study conducted by Reichert et al. did not find any significant difference in mean hospital stay in patients who were operated by VATS decortication versus COD, with mean hospital stay of 28.1 \pm 30.7 days versus $28.6 \pm 25.5$ days respectively ${ }^{14}$. However another study conducted by Hajjar et al, found significantly less hospital stay in VATS patients $9.61 \pm$ 4.1 days versus $21.82 \pm 16.35$ days in COD group and mortality rate was $4 \%$ in VATD group and $0.0 \%$ in open surgery group ${ }^{15}$. Results of these two studies were very different, more over a recent meta-analysis published in 2017 also failed to reach any conclusion regarding superiority of one approach over the other ${ }^{16}$.

Implementing VATD decortication in late stage II and III empyema management has many advantages over open surgery, as some surgeons have noticed earlier and can be considered safely as first line surgical management ${ }^{17}$, in our view with experience and learning, conversion to an open thoracotomy should not be considered as a failure of VATD decortication, but as an exercise of experience in surgical analyses. The present study shows a lower rate of conversion to open decortication as compared to previous studies, which ranged from $29-58 \% 18$, in the recent study, the major cause of conversion was hemorrhage in 1 case. Another 2 cases were converted due to air leakage either due to lung injury during removal of thickened, and adherent thick peel over lung surface being unsuitable for VATD Decortication.

\section{CONCLUSION}

In empyema's patients, VATS Decortication has a definite superiority in stage II and stage III empyema thoracic in terms of amount of blood loss, post-op pain, duration of chest intubation, air leak and hospital stay of the patient. However, operative time was more in VATD group. VATD should be consider as first line surgical management for selected cases of stage II and III empyema thoraces.

\section{CONFLICT OF INTEREST}

This study has no conflict of interest to be declared by any author.

\section{REFERENCES}

1. Chung JH, Lee SH, Kim KT, Jung JS, Son HS, Sun K. Optimal timing of thoracoscopic drainage and decortication for empyema. Ann Thorac Surg 2014; 97(1): 224-29.

2. Marhuenda C, Barceló C, Fuentes I, Guillén G, Cano I, López M, et al. Urokinase versus VATS for treatment of empyema: a randomized multicenter clinical trial. Pediatr 2014; 134(5): e1301-1307.

3. Krenke K, Sadowy E, Podsiadły E, Hryniewicz W, Demkow U, Kulus M. Etiology of parapneumonic effusion and pleural empyema in children. The role of conventional and molecular microbiological tests. Respir Med 2016; 116(1): 28-33.

4. Segerer FJ, Seeger K, Maier A, Hagemann C. Therapy of 645 children with parapneumonic effusion and empyema-A german nationwide surveillance study. ediatr Pulmonol 2017; 52(4): 540-47.

5. Psallidas I, Corcoran JP, Rahman NM. Management of parapneumonic effusions and empyema. In seminars in respiratory and critical care medicine. Thieme Med Pub 2014; 35(6): 715-22.

6. Scarci M, Abah U, Solli P, Page A, Waller D, Van Schil P, et al. EACTS expert consensus statement for surgical management of pleural empyema. Eur J Cardio-thorac Surg 2015; 48(5): 642-53.

7. Huang D, Zhao D, Zhou Y, Liu H, Chen X. Intrapleural fibrinolytic therapy for residual coagulated hemothorax after lung surgery. World J Surg 2016; 40(5): 1121-28.

8. Espinosa CM, Fallat ME, Woods CR, Weakley KE, Marshall GS. An approach to the management of pleural empyema with early video-assisted thoracoscopic surgery and early transition to oral antibiotic therapy. Am Surg 2016; 82(4): 295-301.

9. Striffeler H, Ris HB, Würsten HU, Hof VI, Stirnemann P. Videoassisted thoracoscopic treatment of pleural empyema. A new therapeutic approach. Eur J Cardiothorac Surg 2015; 8(2): 585-88.

10. Reichert M, Pösentrup B, Hecker A, Schneck E, Pons-Kühnemann J, Augustin F, et al. Thoracotomy versus video-assisted thoracoscopic surgery (VATSS) in stage III empyema - an analysis of 217 consecutive patients. Surg Endosc 2017; 32(6): 1-2.

11. Kim BY, Oh BS, Jang WC, Min YI, Park YK, Park JC. Videoassisted thoracoscopic Decortication for management of postpneumonic pleural empyema. Am J Surg 2014; 188(3): 321-24.

12. Balagopal BC, Goutham H, Raju LS. Video assisted thoracoscopic surgery emerging as a primary treatment for empyema thoracis. J Clin Diagnostic Res 2018; 12(3): 1-5.

13. Tong BC, Hanna J, Toloza EM, Onaitis MW, D'Amico TA, Harpole DH, et al. Outcomes of video-assisted thoracoscopic décortication. Ann Thorac Surg 2016; 89(6): 220-25.

14. Reichert M, Hecker M, Witte B, Bodner J, Padberg W, Weigand MA, et al. Stage-directed therapy of pleural empyema. Langenbeck's Arch Surg 2017; 402(1): 15-26.

15. Yu H. Management of pleural effusion, empyema, and lung abscess. Semin Intervent Radiol 2014; 28(1): 75-86.

16. Anstadt MP, Guill CK, Ferguson ER, Gordon HS, Soltero ER, Beall AC Jr. Surgical versus nonsurgical treatment of empy-ema thoracis: An outcomes analysis. Am J Med Sci 2017; 326(2): 9-14.

17. Pan H, He J, Shen J, Jiang L. A meta-analysis of video-assisted thoracoscopic decortication versus open thoracotomy decortication for patients with empyema. J Thorac Dis 2017; 9(7): 1-10.

18. Reichert M, Pösentrup B. Lung decortication in phase III pleural empyema by video-assisted thoracoscopic surgery (VATS)-results of a learning curve study. J Thorac Dis 2018; 10(7): 4311-20. 